\title{
STIMULUS EQUIVALENCE AND SOCIAL CATEGORIZATION IN NORTHERN IRELAND
}

\author{
Attracta McGlinchey \& Michael Keenan \\ University of Ulster at Coleraine
}

\begin{abstract}
Subjects of this study were Catholics and Protestants from Northern Ireland. They included six adults and thirty children; the children were aged between five years and twelve years. Using a mixture of arbitrary and socially loaded stimuli, subjects were taught four conditional discriminations. They were taught firstly to select stimulus B I (arbitrary stimulus) in the presence of A 1 (Protestant stimulus) and to select stimulus B2 (arbitrary stimulus) in the presence of stimulus A2 (Catholic stimulus). They were trained then to select stimulus $\mathrm{Cl}$ (Catholic stimulus) in the presence of B I and to select stimulus C2 (Protestant stimulus) in the presence of B2. An equivalence test was administered subsequently to determine whether these Protestant and Catholic symbols had become related through symmetry and transitivity. Additional tests were administered using arbitrary and nonarbitrary novel stimuli to determine if socially learned relations would compete with the emergence of equivalence relations. Findings suggest that prior social learning can result in equivalence responding not occurring in the testing phase.
\end{abstract}

Key words: social behavior, social categorization, stimulus equivalence, children, Northern Ireland.

When individuals in a community are exposed to commonly arranged social contingencies they acquire patterns of behavior that in tum are used to define group allegiance. Group allegiance is signaled by the language spoken, the national anthems sung, the sports played, flags waved and by different educational practices. Northern Ireland is no exception. To be a native of Northern Ireland implies belonging to one of two communities, Catholic or Protestant. The history of the friction between these two groups dates back to the plantation of Ulster in 1609. In 1921, Ireland was partitioned: Northern Ireland became part of the United Kingdom while the Smith of Ireland became a republic. This divide was not just in terms of land, because the people of Ireland were split also, with Protestants in favour of the union with Britain and most Catholics aspiring toward some association with the rest of Ireland. Since then, 74 years of separate institutions have formalized the differences between the two parts of Ireland.

On July 12, Protestant groups celebrate the victory of King William over King James at the battle of the Boyne in 1690. They march in band parades and fly the British flag (Union Jack) and orange flags, orange being associated with Holland where King William originated. Catholic groups, too, hold traditional parades. On Easter Sunday each year Republicans honor Ireland's dead, in remembrance of the

\section{AUTHORS' NOTE:}

This research was conducted in part fulfillment of the first author's requirements for the degree of Bachelor of Science at the University of Ulster, under the supervision of Dr. M. Keenan. Please address all correspondence to either author at the Department of Psychology, University of Ulster at Coleraine, Coleraine, County Londonderry, N. Ireland, BT52 ISA. 


\section{MCGLINCHEY AND KEENAN}

Easter Rising in 1916. On this day many Nationalists adorn the Easter lily in colors of green, white and gold, and they too march in band parades.

When two cultures have very different beliefs, conflict and prejudice may result. Such is the case with Catholics and Protestants in Northern Ireland. This has an important influence upon children growing up in Northern Ireland. Children may learn to behave with prejudice as a result of social contingencies maintained by members of their religious group.

Studies in the development of prejudice in Ireland are few, even though Ireland has a long history ofconflict. Studies really began with the occurrence of the present troubles in 1969 (see Cairns, 1980, 1982). According to traditional psychological research in Northern Ireland, the development of religious prejudice is based upon stereotyped cues. Stereotyped cues found in Northern Ireland to distinguish Protestants from Catholics include names of individuals and of schools, place of residence, type of sport one plays or watches, flags exhibited and so on. For example, if one were to walk into an unfamiliar area of Northern Ireland, sometimes one has only to look at the colors of the painted paving stones to determine the denomination of the majority of people in the area.

Cairns (1980) contended that the distinction between Catholic and Protestant was an important one for most of the children in Northern Ireland, who by age 11 were able and willing to classify themselves and others. In particular, this program of research asserted that "the Troubles" were dominant in the minds of the children, whether in terms of the violence or in terms of the classification system that underlies the conflict.

Trew (1983) suggested that if denomination were of major importance to those living in Northern Ireland, then denominational group identity would be prominent in most situations. Trew (1981) conducted a study of 609 9- to 11-year-old Catholic subjects in a border area of Northern Ireland, where the level of violence was classed as "high." Children were asked to give 20 answers to the question "What are you?" Overall results showed that $46 \%$ referred to themselves as Catholic, one quarter of these made reference to the fact they were Christians. Eleven-year-olds referred to themselves as Catholic significantly more frequently than 9-year-olds.

With one exception, none of the research on the development of prejudice conducted in Northern Ireland has been from a behavioral perspective. Recently, however, an experiment reported by Watt, Keenan, Cairns, and Barnes (1991) has broken the mold and has opened the door for other behaviorally based research programs interested in social categorization. Their study involves procedures designed for the study of stimulus equivalence, a phenomenon which provides an account for emergent novel behavior.

The novel behavior can be traced to a particular kind of training, however. Specifically, subjects are taught related conditional discriminations-that is, they learn to select stimulus B in the presence of A and stimulus $\mathrm{C}$ in the presence of B; the role of one stimulus depends upon the presence or absence of another stimulus ir the situation. Knowledge of conditional relations enables one to predict with varying accuracy what is likely to happen under given antecedent conditions. In a classi( series of experiments Sidman and his colleagues (e.g., Sidman \& Tailby, 1982) founc that when language-able humans are taught a number of conditional discriminations 


\section{STIMULUS EQUIVALENCE AND SOCIAL CATEGORIZATION}

the stimuli often become related to one another in untrained ways. Specifically, if subjects are taught to match $\mathrm{A} 1$ to $\mathrm{B} 1$ and $\mathrm{B} 1$ to $\mathrm{C} 1$, they will match also $\mathrm{A} 1$ to $\mathrm{A} 1$ (also $\mathrm{Bl}$ to $\mathrm{Bl}$, and $\mathrm{Cl}$ to $\mathrm{Cl}$; reflexivity) $\mathrm{Bl}$ to $\mathrm{Al}$ and $\mathrm{Cl}$ to $\mathrm{Bl}$ (symmetry). In addition, without further training subjects are likely to match $\mathrm{A} 1$ to $\mathrm{C} 1$ (transitivity) and $\mathrm{Cl}$ to $\mathrm{Al}$ (combined symmetry and transitivity). When the three derived relations, reflexivity, symmetry and transitivity are demonstrated, the stimuli are said to constitute an equivalence class. In an equivalence class, two or more stimuli come to have the same functions with respect to one another i.e., they are interchangeable. In ordinary language, it is said that stimuli with interchangeable functions "mean" the same thing; for example, a picture of a dog and the word $d o g$ are said to mean the same thing.

Watt et al. (1991) first demonstrated the application of stimulus equivalence to social categorization using Northern Irish and English students who studied in Northern Ireland. Subjects were trained via a conditional discrimination procedure until three, three-member equivalence classes emerged. The stimuli they used consisted of Catholic names (AI, A2, A3), nonsense syllables (B1, B2, B3), and Protestant symbols $(\mathrm{C} 1, \mathrm{C} 2, \mathrm{C} 3)$. After training $\mathrm{A}$ to Band $\mathrm{B}$ to $\mathrm{C}$, it would be expected normally that subjects would match $\mathrm{C}$ to A (combined symmetry and transitivity). However, in the testing stage, Watt et al. obtained data unlike the usual findings described in the literature on equivalence responding. Using a novel testing procedure they found that some Northern Irish subjects "failed" to respond equivalently. For example, when $\mathrm{Cl}$ (a Protestant symbol) was the sample in a test, the three comparison stimuli comprised A1 and A2 (Catholic names) along with a new stimulus N1 (a typically Protestant name); subjects had not been exposed to N1 before testing. Those subjects who failed to respond equivalently (i.e., who did not select AI) instead selected N 1. In contrast, English subjects, who had less experience with the social significance of the stimuli used in the study responded equivalently.

In a follow-up study on social categorization and stimulus equivalence, Moxon, Keenan, and Hine (1993) examined gender-role stereotyping. They attempted to train relations between stimuli such that each of the three planned equivalence classes would contain stimuli that are stereotypically viewed as opposites (cf. Hayes, 1991). It was found that a number of subjects did not respond equivalently during equivalence testing. This disruption of equivalence responding is similar to the findings reported by Watt et al. (1991). Here also, subjects apparently did not respond equivalently because the experimentally trained relations between stimuli were in competition with previously established relations.

Two further studies have extended the range of nonarbitrary stimuli that are used in an equivalence training procedure. Leslie, Tierney, Robinson, Keenan, Watt, and Barnes (1993) demonstrated that interference with stimulus equivalence class formation could prove a useful diagnostic technique with clinically anxious individuals, and it might also contribute to our understanding of the mechanisms of anxiety. Grey and Barnes (1996) examined further the contribution of stimulus equivalence procedures to the study of attitude formation and attitude change. Findings of these studies suggest that social behavior can be studied employing stimulus equivalence procedures. 


\section{MCGLINCHEY AND KEENAN}

The present study is modeled on the study by Watt et al. (1991). It was designed to investigate whether or not the use of nonarbitrary stimuli in a test of equivalence would disrupt equivalence responding for children and young people living- in Northern Ireland. Due to the fact that subjects in the present study were children, care had to be taken in the selection of stimuli. Specifically, pictures were used as stimuli instead of words, to avoid the implications of reading ability and comprehension. Another difference between this study and that of Watt et al. was that in the present study two, 3-member classes were trained and each class contained stimuli that could be seen as opposites, specifically A 1 (Union Jack-viewed in Northern Ireland as a Protestant stimulus) was trained to BI (arbitrary) and BI to CI (Irish dancer-viewed in Northern Ireland as a Catholic stimulus).

\section{Method}

\section{Subjects}

Subjects included 28 primary school children who were randomly selected from two primary schools, one Catholic and one Protestant. Subjects ages ranged from 5 years 8 months to 11 years 8 months. Two 12-year-old subjects were also selected along with 6 adults (five Catholics and three Protestants).

\section{Stimuli}

The stimuli (6-inch $\mathrm{x}$ 4-inch color photographs) were as follows: AI: Union Jack (i.e., the national flag of the United Kingdom of Northern Ireland and Great Britain); B 1: a man's face; C1: a dancer dressed in a traditional Irish costume; A2: Tricolor (i.e., the national flag of the Republic ofIreland; B2: a man's face (different from BI); C2: a leading Orangeman (i.e., a member of the "Orange Institution which is a voluntary association of English-speaking Protestants, having its origins in the British Isles but now organized throughout the world in defense of Civil and Religious liberty," (Rev. Dr. M.W. Dewar, 1958) ); Xl: Pope John Paul II; YI: a woman's face; X2: Reverend Ian Paisley (i.e., a leading Protestant politician); Y2: a woman's face (different from VI).

\section{Overview of Procedure}

The experimental procedure began with a set of instructions followed by a conditional discrimination procedure in which subjects were taught four conditional discriminations. Next, subjects were given a standard equivalence test. Following this, "novelty" equivalence tests that included arbitrary and nonarbitrary stimuli were administered. These tests included the comparison stimuli that had not been among the stimuli presented during conditional discrimination training. For example, in the presence of sample CI, comparison stimuli sometimes were Al and X1 (a novel stimulus), while at other times they were Al and YI (a novel stimulus); equal numbers of X1 and YI were presented. Similarly, when C2 was the sample, equal numbers of A2-X2 and A2-Y2 were presented as comparisons. Finally, subjects were 


\title{
STIMULUS EQUIVALENCE AND SOCIAL CATEGORIZATION
}

interviewed briefly and asked to identify those pictures they recognized. Those subjects who did not respond equivalently were asked to explain their choices.

\section{Procedure}

Before undertaking the experiment, the experimenter met with the principals of both schools and the experimental procedure was explained and the stimuli examined. Cover letters explaining the rationale of the study were given to parents.

During the sessions each subject sat at a table facing forward and the experimenter sat behind his or her left shoulder. The experimental materials were placed on the table in front of the child. In a given trial, the three stimuli (one sample and two comparisons) were presented on sheets of white paper (11.5 x 16.5 inches). The sample stimulus was positioned in the middle of the page, one inch from the top horizontal edge; the two comparison stimuli were positioned at the bottom of the page, one inch from their respective vertical edges and I-inch from the bottom horizontal edge. The left-right presentation of the comparison stimuli was randomized across trials to prevent the child from responding on the basis of stimulus position.

The materials used in the test phase were identical to those used in the training phase, except that the sample stimuli were stimuli that previously had been comparisons during the conditional discrimination training.

The experimenter began the experimental procedure by saying:

\begin{abstract}
We are going to play a little game. I will show you a series of cards, each containing three pictures, one picture at the top and two pictures at the bottom. Your task is to find which of the pictures at the bottom matches the one at the top. I will tell you if your choice is wrong or right. Do you understand what you have to do? For every correct answer move one bead on the abacus. When you have ten answers correct, then you will get a prize.
\end{abstract}

When the children responded correctly ten times, they could choose a prize from a variety of stickers of cartoon characters.

Stage 1. Training with continuous feedback. Children were trained individually, and the same training sequence was used for all. In the first stage of training children were taught baseline conditional discriminations. Specifically, they were taught to select B 1 in the presence of A 1 and to select B2 in the presence of A2 (Figure 1). When two successive cycles of this combination of sample and comparison stimuli had been correctly completed (in other words, when twenty successive correct responses had been made), the second part of Stage 1 commenced. In this part of training the children were taught to select $\mathrm{C} 1$ in the presence of Bland to select C2 in the presence of B2. Similarly, two successive cycles of this new combination of sample and comparison stimuli had to be successfully completed before transition to the next part of the experiment.

Stage 2. Training with intermittent feedback. At the onset of this stage, subjects were informed that they would not always be told whether their responses were correct or not. In fact, feedback was available for only 50 percent of responses. 


\section{MCGLINCHEY AND KEENAN}
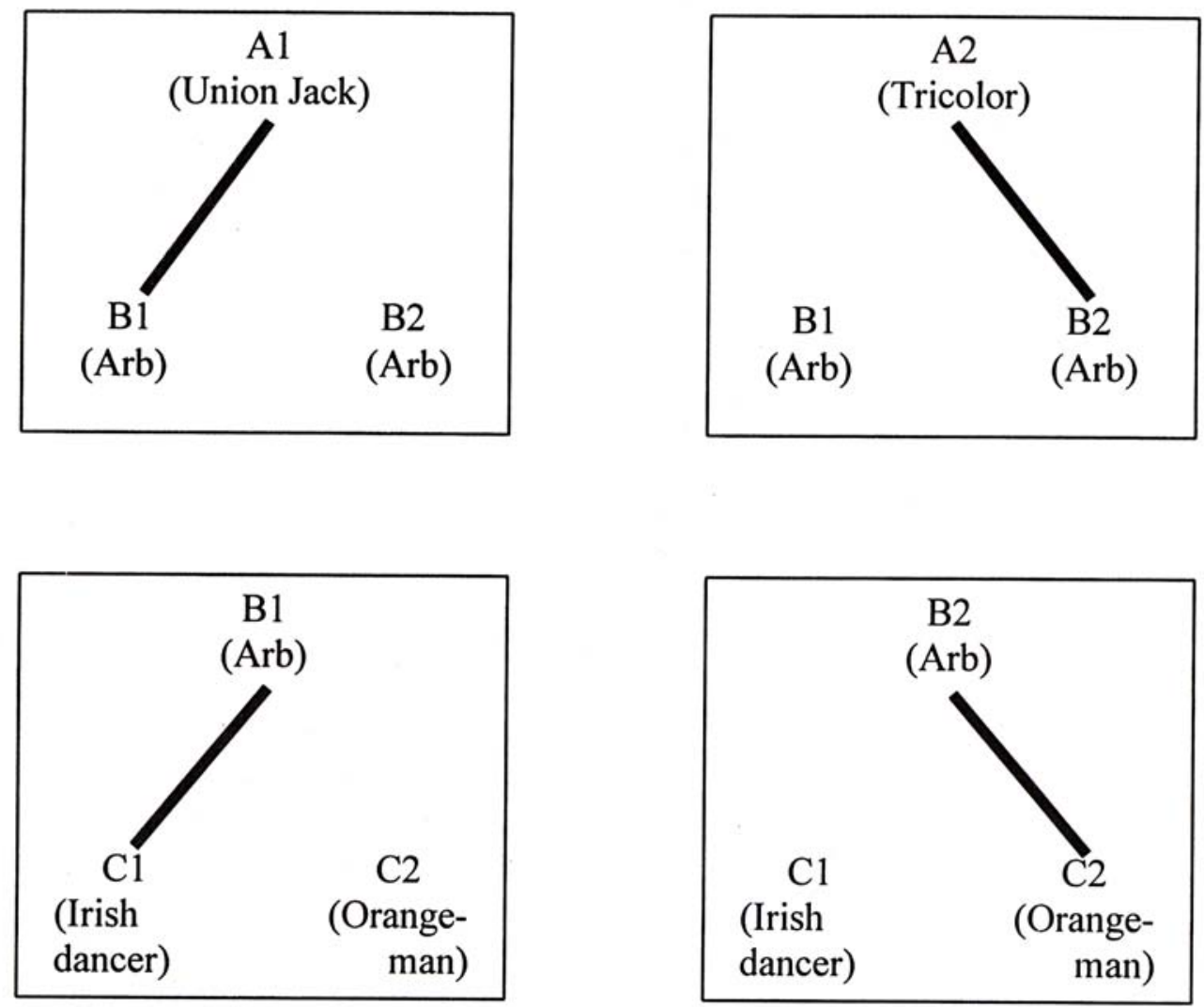

Figure 1. Stimuli used in the conditional discrimination training. Solid lines represent trained relations.

The stimulus combinations described in Stage 1 were all presented in random order during this condition. Each stimulus combination was presented twice and if less than 90 percent of responses were correct, the procedure reverted back to the start of Stage 1. If performance was 90 percent or more, then the next stage began immediately.

Stage 3. Testing. Each subject was exposed to three test procedures: Test 1, Test 2, and Test 3. For some subjects, Test 3 was presented before Test 2. Tests were repeated several times to determine consistency in choice. Training and testing were completed in the same session, with sessions lasting approximately 30 minutes, depending on the amount of training required to learn and maintain baseline conditional discriminations.

Test 1. This was a test of symmetry. Here, B1, B2, C1, C2 each served as samples on eight occasions, and the comparison stimuli were AI-A2, AI-A2, BI-B2, BI-B2 respectively. Subjects who obtained 100 percent accuracy on Test 1 were given the next test. 
STIMULUS EQUIVALENCE AND SOCIAL CATEGORIZATION

Test 2
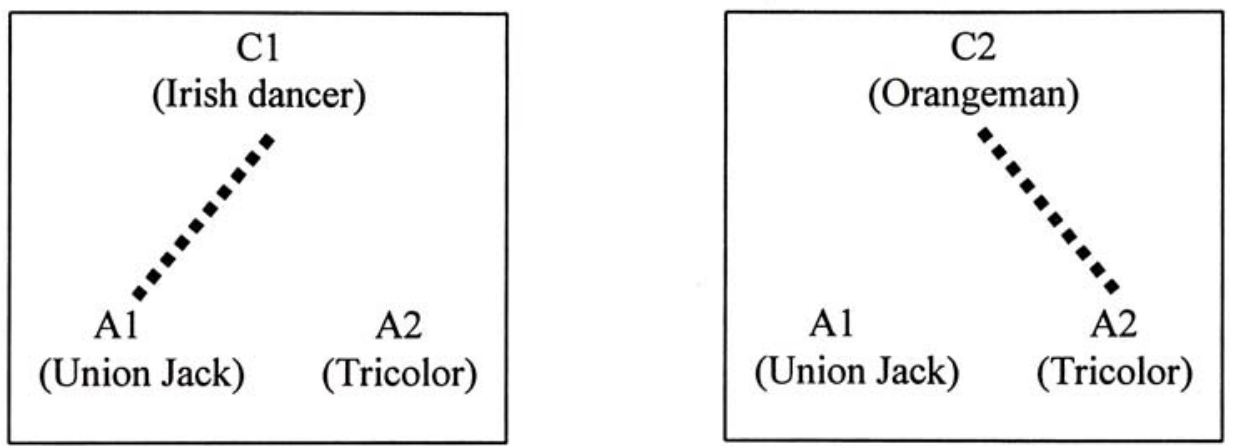

Test 3 containing arbitrary and nonarbitrary stimuli
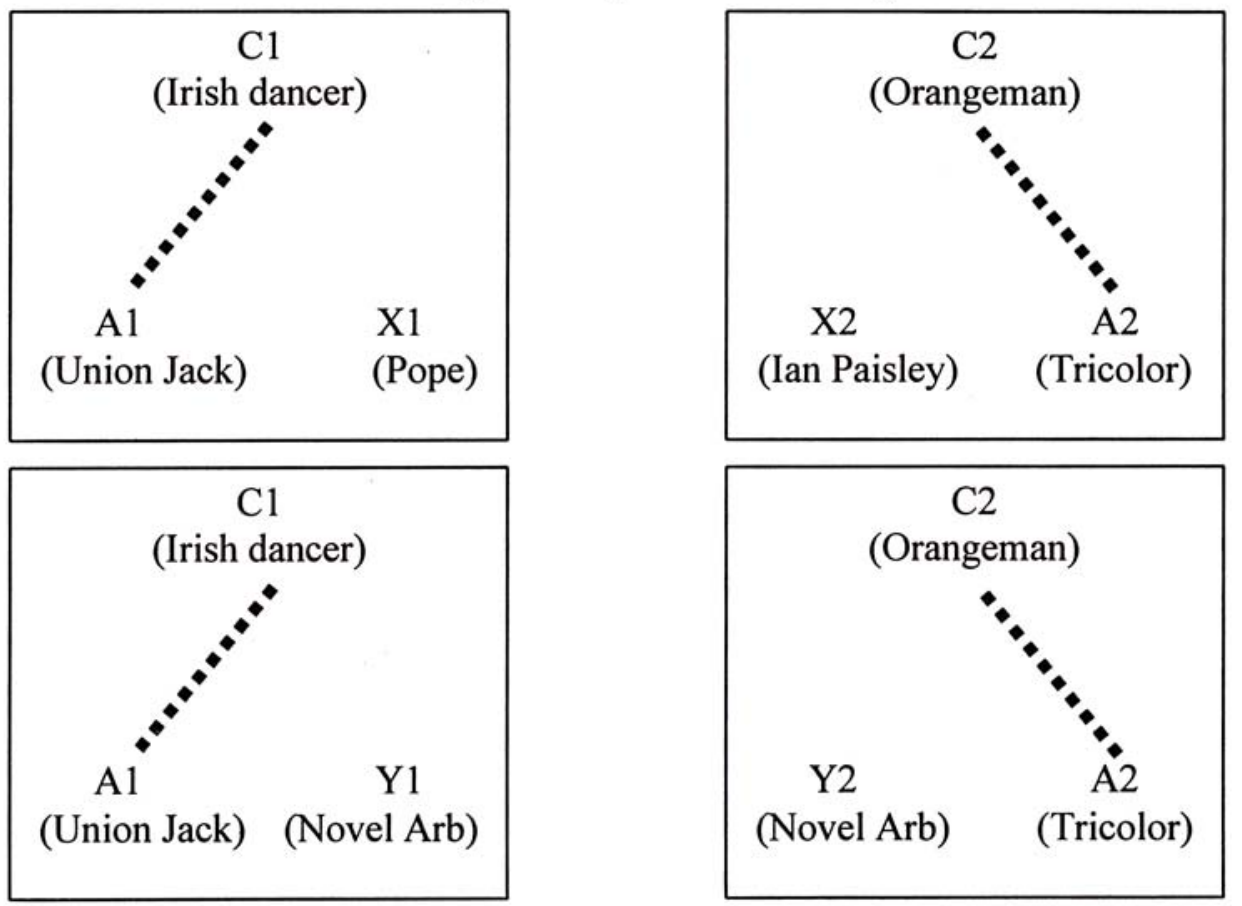

Figure 2. Test stimulus presentations. Broken lines represent expected emergent relations.

Test 2. This was a test of combined symmetry and transitivity. In this test, CI and $\mathrm{C} 2$ served as sample stimuli and comparison stimuli were A1 and A2; there were 10 presentations each ofCI and $\mathrm{C} 2$.

Test 3 . In this test the combinations of stimuli used were as follows: $\mathrm{C} 1$ : AI-X1; C1: AI-YI; C2: A2-X2; C2: A2-Y2 (stimuli in bold lettering were samples and the other hyphenated pairs of stimuli were comparisons). There were eight presentations each of CI and C2. Subjects moved from Test 2 to Test 3, and vice versa, when responding had stabilized.

Figure 2 illustrates the test presentations in Tests 2 and 3. 


\section{MCGLINCHEY AND KEENAN}

Inter observer reliability. To assess the reliability of results obtained by the experimenter, an observer was present during $50 \%$ of sessions. The observer was placed behind the subject and recorded his or her responses. When these results were compared with those of the experimenter, they were found to be identical.

\section{Results}

During training (i.e., matching $\mathrm{A}$ to Band $\mathrm{B}$ to $\mathrm{C}$ ) all subjects responded with 90-100 percent accuracy. All subjects reached the 100 percent criterion on their first exposure to the symmetry test.

Tables 1 through 4 show the results of the Catholic and Protestant school children on Tests 2 and 3. Twenty-three of the primary school children responded equivalently on both these tests. These children chose Al when CI was the sample and A2 when $\mathrm{C} 2$ was the sample. Of these, 14 were Protestant (Tables 1 and 3 respectively) and nine were Catholic (Tables 2 and 4 respectively).

Two children (Subjects S25 \& S27) responded equivalently on Test 2 (Table 2) but differentially on Test 3 (Table 4). In Test 3, these Catholic children selected Ian Paisley (X2) in the presence of the sample stimulus Orangeman (C2). For all other presentations containing novel stimuli, these subjects responded equivalently.

Two others (Subjects S16 \& S17) responded equivalently on Test 2 with haphazard responding on Test 3 . In both cases, Test 3 had been administered before Test 2. The tests were repeated several times and for both subjects there was equivalence responding on Test 2 while responding on Test 3 varied from trial to trial.

One of the primary school children (Subject S21) did not respond equivalently during Test 2 with differential responding on Test 3, in other words in the presence of sample stimulus C2 (Orangeman) this subject chose the comparison stimulus X2 (Ian Paisley). For all other presentations containing novel stimuli, this subject responded equivalently.

From Tables 5 and 6, it can be seen that all of the adults and both the 12-yearolds responded nonequivalently on Tests 2 and 3 .

Interviews following the testing period established which, if any, of the stimuli the subjects recognized and could identify. These varied from subject to subject, most knew at least a few. 


\begin{tabular}{|c|c|c|c|c|}
\hline Subject & C1-A1 & C1-A2 & C2-A1 & C2-A2 \\
\hline S1 & $\mathbf{1 0}$ & 0 & 0 & $\mathbf{1 0}$ \\
\hline S2 & $\mathbf{1 0}$ & 0 & 0 & $\mathbf{1 0}$ \\
\hline S3 & $\mathbf{1 0}$ & 0 & 0 & $\mathbf{1 0}$ \\
\hline S4 & $\mathbf{1 0}$ & 0 & 0 & $\mathbf{1 0}$ \\
\hline S5 & $\mathbf{1 0}$ & 0 & 0 & $\mathbf{1 0}$ \\
\hline S6 & $\mathbf{1 0}$ & 0 & 0 & $\mathbf{1 0}$ \\
\hline S7 & $\mathbf{1 0}$ & 0 & 0 & $\mathbf{1 0}$ \\
\hline S8 & $\mathbf{1 0}$ & 0 & 0 & $\mathbf{1 0}$ \\
\hline S9 & $\mathbf{1 0}$ & 0 & 0 & $\mathbf{1 0}$ \\
\hline S10 & $\mathbf{1 0}$ & 0 & 0 & $\mathbf{1 0}$ \\
\hline S11 & $\mathbf{1 0}$ & 0 & 0 & $\mathbf{1 0}$ \\
\hline S12 & $\mathbf{1 0}$ & 0 & 0 & $\mathbf{1 0}$ \\
\hline S13 & $\mathbf{1 0}$ & 0 & 0 & $\mathbf{1 0}$ \\
\hline S14 & $\mathbf{1 0}$ & 0 & 0 & $\mathbf{1 0}$ \\
\hline
\end{tabular}

Table 1. The responses of the Protestant primary school children in Test 2. Bold type in shaded columns represents expected emergent relations.

\begin{tabular}{|c|c|c|c|c|}
\hline Subject & C1-A1 & Cl-A2 & C2-Al & C2-A2 \\
\hline S15 & $\mathbf{1 0}$ & 0 & 0 & $\mathbf{1 0}$ \\
\hline S16 & $\mathbf{1 0}$ & 0 & 0 & $\mathbf{1 0}$ \\
\hline S17 & $\mathbf{1 0}$ & 0 & 0 & $\mathbf{1 0}$ \\
\hline S18 & $\mathbf{1 0}$ & 0 & 0 & $\mathbf{1 0}$ \\
\hline S19 & $\mathbf{1 0}$ & 0 & 0 & $\mathbf{1 0}$ \\
\hline S20 & $\mathbf{1 0}$ & 0 & 0 & $\mathbf{1 0}$ \\
\hline S21 & $\mathbf{0}$ & 10 & 10 & $\mathbf{0}$ \\
\hline S22 & $\mathbf{1 0}$ & 0 & 0 & $\mathbf{1 0}$ \\
\hline S23 & $\mathbf{1 0}$ & 0 & 0 & $\mathbf{1 0}$ \\
\hline S24 & $\mathbf{1 0}$ & 0 & 0 & $\mathbf{1 0}$ \\
\hline S25 & $\mathbf{1 0}$ & 0 & 0 & $\mathbf{1 0}$ \\
\hline S26 & $\mathbf{1 0}$ & 0 & 0 & $\mathbf{1 0}$ \\
\hline S27 & $\mathbf{1 0}$ & 0 & 0 & $\mathbf{1 0}$ \\
\hline S28 & $\mathbf{1 0}$ & 0 & 0 & $\mathbf{1 0}$ \\
\hline
\end{tabular}

Table 2. The responses of the Catholic primary school children on Test 2. Bold type in shaded columns represents expected emergent relations. 


\begin{tabular}{|c|c|c|c|c|c|c|c|c|}
\hline Subject & C1-A1 & C1-X1 & C2-A2 & C2-X2 & C1-A1 & C1-Y1 & C2-A2 & C2-Y2 \\
\hline S1 & $\mathbf{8}$ & 0 & $\mathbf{8}$ & 0 & $\mathbf{8}$ & 0 & $\mathbf{8}$ & 0 \\
\hline S2 & $\mathbf{8}$ & 0 & $\mathbf{8}$ & 0 & $\mathbf{8}$ & 0 & $\mathbf{8}$ & 0 \\
\hline S3 & $\mathbf{8}$ & 0 & $\mathbf{8}$ & 0 & $\mathbf{8}$ & 0 & $\mathbf{8}$ & 0 \\
\hline S4 & $\mathbf{8}$ & 0 & $\mathbf{8}$ & 0 & $\mathbf{8}$ & 0 & $\mathbf{8}$ & 0 \\
\hline S5 & $\mathbf{8}$ & 0 & $\mathbf{8}$ & 0 & $\mathbf{8}$ & 0 & $\mathbf{8}$ & 0 \\
\hline S6 & $\mathbf{8}$ & 0 & $\mathbf{8}$ & 0 & $\mathbf{8}$ & 0 & $\mathbf{8}$ & 0 \\
\hline S7 & $\mathbf{8}$ & 0 & $\mathbf{8}$ & 0 & $\mathbf{8}$ & 0 & $\mathbf{8}$ & 0 \\
\hline S8 & $\mathbf{8}$ & 0 & $\mathbf{8}$ & 0 & $\mathbf{8}$ & 0 & $\mathbf{8}$ & 0 \\
\hline S9 & $\mathbf{8}$ & 0 & $\mathbf{8}$ & 0 & $\mathbf{8}$ & 0 & $\mathbf{8}$ & 0 \\
\hline S10 & $\mathbf{8}$ & 0 & $\mathbf{8}$ & 0 & $\mathbf{8}$ & 0 & $\mathbf{8}$ & 0 \\
\hline S11 & $\mathbf{8}$ & 0 & $\mathbf{8}$ & 0 & $\mathbf{8}$ & 0 & $\mathbf{8}$ & 0 \\
\hline S12 & $\mathbf{8}$ & 0 & $\mathbf{8}$ & 0 & $\mathbf{8}$ & 0 & $\mathbf{8}$ & 0 \\
\hline S13 & $\mathbf{8}$ & 0 & $\mathbf{8}$ & 0 & $\mathbf{8}$ & 0 & $\mathbf{8}$ & 0 \\
\hline S14 & $\mathbf{8}$ & 0 & $\mathbf{8}$ & 0 & $\mathbf{8}$ & 0 & $\mathbf{8}$ & 0 \\
\hline
\end{tabular}

Table 3. The responses of the Protestantprimary school children on Test 3. Bold type in shaded columns represents expected emergent relations.

\begin{tabular}{|c|c|c|c|c|c|c|c|c|}
\hline Subject & C1-A1 & C1-X1 & C2-A2 & C2-X2 & C1-A1 & C1-Y1 & C2-A2 & C2-Y2 \\
\hline S15 & $\mathbf{8}$ & 0 & $\mathbf{8}$ & 0 & $\mathbf{8}$ & 0 & $\mathbf{8}$ & 0 \\
\hline S16 & $\mathbf{4}$ & 4 & $\mathbf{6}$ & 2 & $\mathbf{2}$ & 6 & $\mathbf{6}$ & 2 \\
\hline S17 & $\mathbf{6}$ & 2 & $\mathbf{2}$ & 6 & $\mathbf{2}$ & 6 & $\mathbf{4}$ & 4 \\
\hline S18 & $\mathbf{8}$ & 0 & $\mathbf{8}$ & 0 & $\mathbf{8}$ & 0 & $\mathbf{8}$ & 0 \\
\hline S19 & $\mathbf{8}$ & 0 & $\mathbf{8}$ & 0 & $\mathbf{8}$ & 0 & $\mathbf{8}$ & 0 \\
\hline S20 & $\mathbf{8}$ & 0 & $\mathbf{8}$ & 0 & $\mathbf{8}$ & 0 & $\mathbf{8}$ & 0 \\
\hline S21 & $\mathbf{8}$ & 0 & $\mathbf{0}$ & $\mathbf{8}$ & $\mathbf{8}$ & 0 & $\mathbf{8}$ & 0 \\
\hline S22 & $\mathbf{8}$ & 0 & $\mathbf{8}$ & 0 & $\mathbf{8}$ & 0 & $\mathbf{8}$ & 0 \\
\hline S23 & $\mathbf{8}$ & 0 & $\mathbf{8}$ & 0 & $\mathbf{8}$ & 0 & $\mathbf{8}$ & 0 \\
\hline S24 & $\mathbf{8}$ & 0 & $\mathbf{8}$ & 0 & $\mathbf{8}$ & 0 & $\mathbf{8}$ & 0 \\
\hline S25 & $\mathbf{8}$ & 0 & $\mathbf{0}$ & $\mathbf{8}$ & $\mathbf{8}$ & 0 & $\mathbf{8}$ & 0 \\
\hline S26 & $\mathbf{8}$ & 0 & $\mathbf{8}$ & 0 & $\mathbf{8}$ & 0 & $\mathbf{8}$ & 0 \\
\hline S27 & $\mathbf{8}$ & 0 & $\mathbf{0}$ & $\mathbf{8}$ & $\mathbf{8}$ & 0 & $\mathbf{8}$ & 0 \\
\hline S28 & $\mathbf{8}$ & 0 & $\mathbf{8}$ & 0 & $\mathbf{8}$ & 0 & $\mathbf{8}$ & 0 \\
\hline
\end{tabular}

Table 4. The responses of the Catholic primary school children on Test 3. Bold type in shaded columns represents expected emergent relations. 


\section{STIMULUS EQUIVALENCE AND SOCIAL CATEGORIZATION}

\begin{tabular}{|c|c|c|c|c|}
\hline Subject & C1-A1 & C1-A2 & C2-A1 & C2-A2 \\
\hline S29 & $\mathbf{0}$ & 10 & 10 & $\mathbf{0}$ \\
\hline S30 & $\mathbf{0}$ & 10 & 10 & $\mathbf{0}$ \\
\hline S31 & $\mathbf{0}$ & 10 & 10 & $\mathbf{0}$ \\
\hline S32 & $\mathbf{0}$ & 10 & 10 & $\mathbf{0}$ \\
\hline S33 & $\mathbf{0}$ & 10 & 10 & $\mathbf{0}$ \\
\hline S34 & $\mathbf{0}$ & 10 & 10 & $\mathbf{0}$ \\
\hline S35 & $\mathbf{0}$ & 10 & 10 & $\mathbf{0}$ \\
\hline S36 & $\mathbf{0}$ & 10 & 10 & $\mathbf{0}$ \\
\hline
\end{tabular}

Table 5. The responses of the adult and 12-year-old subjects on Test 2. Bold type in shaded columns represents expected emergent relations.

\begin{tabular}{|c|c|c|c|c|c|c|c|c|}
\hline Subject & C1-A1 & C1-X1 & C2-A2 & C2-A2 & C1-A1 & C1-Y1 & C2-A2 & C2-Y2 \\
\hline S29 & $\mathbf{0}$ & 8 & $\mathbf{0}$ & 8 & $\mathbf{0}$ & 8 & $\mathbf{0}$ & 8 \\
\hline S30 & $\mathbf{0}$ & 8 & $\mathbf{0}$ & $\mathbf{8}$ & $\mathbf{0}$ & $\mathbf{8}$ & $\mathbf{0}$ & $\mathbf{8}$ \\
\hline S31 & $\mathbf{0}$ & $\mathbf{8}$ & $\mathbf{0}$ & $\mathbf{8}$ & $\mathbf{0}$ & $\mathbf{8}$ & $\mathbf{0}$ & $\mathbf{8}$ \\
\hline S32 & $\mathbf{0}$ & $\mathbf{8}$ & $\mathbf{0}$ & $\mathbf{8}$ & $\mathbf{0}$ & $\mathbf{8}$ & $\mathbf{0}$ & $\mathbf{8}$ \\
\hline S33 & $\mathbf{0}$ & $\mathbf{8}$ & $\mathbf{0}$ & $\mathbf{8}$ & $\mathbf{0}$ & $\mathbf{8}$ & $\mathbf{0}$ & $\mathbf{8}$ \\
\hline S34 & $\mathbf{0}$ & $\mathbf{8}$ & $\mathbf{0}$ & $\mathbf{8}$ & $\mathbf{0}$ & $\mathbf{8}$ & $\mathbf{0}$ & $\mathbf{8}$ \\
\hline S35 & $\mathbf{0}$ & $\mathbf{8}$ & $\mathbf{0}$ & $\mathbf{8}$ & $\mathbf{0}$ & $\mathbf{8}$ & $\mathbf{0}$ & $\mathbf{8}$ \\
\hline S36 & $\mathbf{0}$ & $\mathbf{8}$ & $\mathbf{0}$ & $\mathbf{8}$ & $\mathbf{0}$ & $\mathbf{8}$ & $\mathbf{0}$ & $\mathbf{8}$ \\
\hline
\end{tabular}

Table 6. The responses ofthe adult and twelve-year-old subjects on Test 3. Bold type in shaded columns represents expected emergent relations. 


\section{MCGLINCHEY AND KEENAN}

\section{Discussion}

The present study was designed to investigate whether or not the use of nonarbitrary stimuli in a test of equivalence would disrupt equivalence responding for children and young people living in Northern Ireland. Disruption of equivalence responding did occur in $36 \%$ of cases. However this appeared in two different ways. For all of the younger children who did not respond equivalently, differential responding occurred in Test 3 which contained novel stimuli. None of the older children or adults responded equivalently in either the standard equivalence test or in the novelty test. Collectively these findings add further support for the notion that standard equivalence testing can be disrupted by prior social learning (Watt et aI., 1991; Leslie et aI., 1993; Moxon et aI., 1993; Grey \& Barnes, 1996). Further, individuals with the most extreme histories of social learning contrary to the experimental training were those least likely to respond equivalently when stimulus sets were mismatched.

Since there was no independent evidence of equivalence responding, as shown by the results of the standard equivalence test, it might be argued that these subjects were unable to respond equivalently. However, this would be an unusual argument given that (a) they responded with a high degree of efficiency on the symmetry tests, and (b) the procedures used were no more complicated than those described in the numerous research articles published with adults. A more plausible account is that they did not respond equivalently, not that they could not. Furthermore, the consistency in their responses indicates that the construction of the testing environment directly controlled the selection of stimuli.

One cannot argue that the novel stimuli included in the tests disrupted equivalence responding simply because they were novel. For those subjects who chose some of the novel stimuli (i.e., they responded differently if the subject had social experience than if they did not), there was consistency in choice. For those subjects who chose all novel stimuli, the interview afterwards revealed why this happened. For example, in the presence of sample stimulus C2 (Orangeman), stimulus X2 (Ian Paisley) was chosen and stimulus A2 (Tricolor) was not chosen; subjects said that they did this because the stimuli C2 and X2 "go together" and the stimuli $\mathrm{C} 2$ and A2 do not. Arbitrary novel stimuli were selected in preference to the expected equivalence relation because the stimuli comprising the putative equivalence relation were viewed as opposites and therefore not considered as a match. For example, in the presence of sample stimulus $\mathrm{Cl}$ (Irish dancer), the stimulus X1 (a woman's face) was selected and the indirectly trained relation, Al (Union Jack), was not selected because subjects argued that an Irish dancer and the British flag had nothing in common, therefore the other comparison stimulus "must be the match."

Interviews with the primary school children revealed that not all the children were familiar with all the stimuli. However, those subjects who were unable to name all the stimuli but who were familiar with, for example, the Union Jack (A 1), the Tricolor (A2), and the Irish dancer (C1) still chose the British flag and not the Irish flag in the presence of the Irish dancer (as they had been indirectly trained to do). 


\section{STIMULUS EQUIVALENCE AND SOCIAL CATEGORIZATION}

This would suggest that it is not sufficient to be able to name the stimuli. More importantly, one must have learned the relation between these stimuli (i.e., in the social context of Northern Ireland, Irish flag "goes with" Irish dancer).

As a further example, consider the performance of subject S20. Although he selected Ian Paisley (X2) in the presence of the Orangeman (C2), the interview revealed that he could not verbalize the Protestant stimulus (C2) as being an Orangeman. His reason for choosing Ian Paisley was that Paisley sometimes marches in parades similar to those depicted in the photograph (C2). This reiterates what has already been said that it is neither sufficient nor indeed necessary to be able to name the stimuli in question. Subtle cues in our environment may be sufficient for us to determine one's religious denomination, so subtle in fact that we may not even be aware of them, or that we are using such indicators. Although subject S20 was sure that Ian Paisley and the Orangeman belonged to the same category, he could not accurately verbalize why he thought this was so.

The present procedures and results might be relevant to a recent interpretation of stimulus equivalence in terms of relational control. The relational frame account of stimulus equivalence developed by Hayes $(1991,1992)$ goes beyond a simple description of stimulus equivalence. Its concepts describe a subject's current derived responses and also the history of relational responding that makes the current derived performance possible (Barnes, 1994). This account of stimulus equivalence views it as a result of prolonged exposure to the contingencies of reinforcement operating in the verbal community. Consider, for example, when a child is learning the name of a new object, the parent points to the object and asks the child, "What is that?" At first the child may be unsure and hesitate, the parent prompts the child saying, "That is a dog!" Again the child is asked, "What is that?" If the child responds "That's a dog!" then the child is reinforced with perhaps, "Well done, that's right!" and also maybe hugs or kisses. Further, when the child is asked "Where is the dog?" and the child accurately points to or touches the dog, it can be said that the child has learned that a dog and the spoken word $\operatorname{dog}$ "mean the same thing."

When a child is taught a large number of word-object and object-word relations and is then exposed to the conditional discrimination procedure, relational cues provided by this context may bring the relational frame of co-ordination to bear on stimuli (Barnes 1994). Such an extensive history of arbitrarily applicable relational responding, especially in the context of language training may afford humans a strong behavioral disposition for equivalence responding. In other words when human subjects are exposed to the relevant reinforcement contingencies they will very likely display equivalence.

The nature of the present study ensures that stimuli are considered in the frame of co-ordination, that is to say, the instructions given to the subjects at the beginning of the experiment indicate that they should find the comparison stimuli that is the match of the sample stimulus. Consider the subject who has been socialized with regard to the nature of Catholic and Protestant stimuli and is instructed to "choose one of the pictures at the bottom," having been reinforced to respond in a certain manner; for example, if Al (Protestant) then Bl (arbitrary), if B1 then $\mathrm{Cl}$ (Catholic). If this subject chooses A 1 in the presence of $\mathrm{C}$, this subject may be responding in a relational frame of oppositeness. In effect, the instructions in the present experiment 


\section{MCGLINCHEY AND KEENAN}

act as a control device, all subjects are to respond in accordance with the relational frame of co-ordination (i.e., sameness). Thus, one can speculate that those subjects who responded equivalently were responding according to the relational frame of coordination, as instructed at the outset. On the other hand, those subjects who did not respond equivalently, it could be argued, were responding in accordance with the relational frame of co-ordination previously acquired in a social context (Catholic matches Catholic and Protestant matches Protestant).

Within the social context of the Northern Irish conflict, the Protestant and Catholic stimuli used in the conditional discrimination procedures may have been seen by some subjects as opposites. On the basis of prior social training, therefore, those subjects who failed to respond equivalently on both the equivalence test and novelty tests were responding in accordance with the relational frame of coordination consistent with the social context. This interpretation was supported by subjects' responses in the interview afterwards. In the case of the arbitrary novelty test, those subjects who did not respond equivalently chose the novel arbitrary stimulus because the other stimulus, which had been indirectly trained, was seen to be opposite (the instructions were to find the picture at the bottom that "matched" the one at the top). Also, subjects appeared to ascribe functions to novel stimuli based on the structure of the task at hand (e.g., during the interview, subject S31 thought that one of the novel arbitrary stimuli was Rhonda Paisley (daughter of lan Paisley), that is, a Protestant stimulus to go with Protestant stimulus Orangeman (C2).

On a more general note, some interesting findings arose during acquisition. For example, the most difficult part of the training (as judged by the number of training trials required) for the younger subjects was the first half of training (training A 1 to $\mathrm{B} 1$ and $\mathrm{A} 2$ to B2). However, for the twelve-year-olds and the adults the second half of training (training $\mathrm{B} 1$ to $\mathrm{C} 1$ and $\mathrm{B} 2$ to $\mathrm{C} 2$ ) was the most difficult. Furthermore, after $\mathrm{B}$ to $\mathrm{C}$ was trained the subsequent stage containing mixed trials of $\mathrm{A}-\mathrm{B}$ and $\mathrm{B}-\mathrm{C}$ showed that the $\mathrm{A}$ to $\mathrm{B}$ relations had become confused and training had to begin again. This finding would suggest that disruption of relations had already begun, in other words, some subjects having matched Al (Union Jack/Protestant stimulus) to $\mathrm{Bl}$ (arbitrary), had difficulty then pairing Bl and $\mathrm{Cl}$ (Irish dancer/Catholic stimulus).

The findings of the present study are in stark contrast with much of the traditional equivalence literature. In those studies where equivalence failed to emerge, subjects were either nonhumans (Sidman, Rauzin, Lazar, Cunningham, Tailby, \& Carrigan, 1982) or language-disabled humans (Devany, Hayes, \& Nelson, 1986). In the present study, however, equivalence did not emerge for normal subjects. Further, the tests employed differentiated between subjects in terms of their social learning history, highlighting the potential of the stimulus equivalence paradigm to account for other social phenomena (cf. McGlinchey, Dillenburger \& Keenan, 1997). 


\section{STIMULUS EQUIVALENCE AND SOCIAL CATEGORIZATION}

\section{REFERENCES}

Barritt, D. P., \& Carter, C. F. (1972). The Northern Ireland problem. 2nd ed. Oxford: Oxford University Press.

Barnes, D. (1994). Stimulus equivalence and relational frame theory. The Psychological Record, 44, 91124.

Barnes, D., \& Holmes, Y. (1991). Radical behaviorism, stimulus equivalence and human cognition. The Psychological Record, 41, 19-31.

Billig, M. (1976). Social psychology and intergroup relations. European Monographs in Social Psychology, No. 9, London: Academic Press.

Burton, F. (1978). The politics oflegitimacy. London: Routledge \& Kegan Paul.

Cairns, E. (1980). The development of ethnic discrimination in young children in Northern Ireland. In J. Harbison and J. Harbison (Eds.). Children and young people in a society under stress. London: Open Books.

Cairns, E. (1982). Intergroup conflict in Northern Ireland. In H. Tajfel (Ed.). Social identity and intergroup relations. London: Cambridge University Press.

Cairns, E. (1987). Caught in crossfire: Children and the Northern Ireland conflict. Belfast, Northern Ireland: Appletree Press.

Cairns, E. \& Mercer, G. W. (1978). Adolescent social identity in Northern Ireland: The importance of denominational identity. Unpublished doctoral dissertation, New University of Ulster.

Catania, A. C. (1984). Learning. Englewood Cliffs, NJ: Prentice-Hall.

Devany, J. M., Hayes, S. C., \& Nelson, R. O. (1986). Equivalence class formation in language-able and language-disabled children. Journal ofthe Experimental Analysis of Behavior, 46, 243-257. http://dx.doi.org/10.1901/jeab.1986.46-243

Easthope, G. (1976). Religious war in Northern Ireland. Sociology, 10 (3), 427-450. http://dx.doi.org/10.1177/003803857601000303

Epstein, A. L. (1978). Ethos and identity. London: Tavistock.

Fields, L., Adams, B. J., Verhave, T., \& Newman, S. (1990). The effects of nodality on the formation of equivalence classes. Journal of the Experimental Analysis of Behavior, 53, 345-358. http://dx.doi.org/10.1901/jeab.1990.53-345

Gamble, R. (1982). A critical and experimental study of colour preference. Americal Journal of Psychology, 54, 385-394.

Grant, L., \& Evans, A. (1994). Principles of behavior analysis . Harper Collins College Publishers.

Grey, I. M., \& Barnes, D. (1996). Stimulus equivalence and attitudes. The Psychological Record, 46, 243-270.

Hayes, S. C. (1991). A relational control theory of stimulus equivalence. In L. J. Hayes \& P. N. Chase (Eds.), Dialogues on verbal behavior: The first international institute on verbal relations. Reno, NV: Context Press.

Hayes, S. C. (1992). Verbal relations, time and suicide. In S. C. Hayes \& L. J. Hayes (Eds.), Understanding verbal relations. Reno, NV: Context Press.

Leslie, 1. C., Tierney, K. 1., Robinson, P., Keenan, M., Watt, A., \& Barnes, D. (1993). Differences between clinically anxious and nonanxious subjects in a stimulus equivalence training task involving threat words. The Psychological Record, 43, 153-161.

LeVine, R. A., \& Campbell, D. T. (1972). Ethnocentrism: Theories of conflict, ethnic attitudes and group behavior. New York: Wiley.

McGlinchey, A., Dillenburger, K., \& Keenan, M. (1997). Child sexual abuse and stimulus equivalence--preliminary research into the development of a covert screening procedure. Paper presented at the third meeting ofEMEAB, Dublin.

McWhirter, L. (1982). Northern Irish children's conceptions of crime. The Howard Journal, 21, 167177. http://dx.doi.org/10.1111/j.1468-2311.1982.tb00462.x

McWhirter, L. (1983). Contact and conflict: The question of integrated education. Irish Journal of Psychology, 6, 13-27. http://dx.doi.org/10.1080/03033910.1983.10557654

McWhirter, L., \& Gamble, R. (1982). Development of ethnic awareness in the absence of physical cues. Irish Journal ofPsychology, 5, 109-127. http://dx.doi.org/10.1080/03033910.1982.10557650

Moore, R. (1972). Race relations in the Six Counties: Colonialism, industrialization and stratification in Ireland. Race, 14, 21-42. http://dx.doi.org/10.1177/030639687201400103

Moxon, P., Keenan, M., \& Hine, L. (1993). Gender-role stereotyping and stimulus equivalence. The Psychological Record, 43, 381-394. 


\section{MCGLINCHEY AND KEENAN}

Reese, H. W. (1991). Mentalistic approaches to verbal behavior. In L. J. Hayes \& P. N. Chase (Eds.), Dialogues on verbal behavior (pp. 151-177). Reno, NV: Context Press.

Sidman, M., Kirk, B., \& Willson-Morris, M. (1985). Six-member stimulus classes generated by conditional discrimination procedures. Journal of the Experimental Analysis of Behavior. 43. 21 42. http://dx.doi.org/10.1901/jeab.1985.43-21

Sidman, M., Rauzin, R., Lazar, R., Cunningham, S., Tailby, W., \& Carrigan, P. (1982). A search for symmetry in the conditional discriminations of rhesus monkeys, baboons, and children. Journal of the Experimental Analysis of Behavior, 37, 23-44. http://dx.doi.org/10.1901/jeab.1982.37-23

Sidman, M., \& Tailby, W. (1982). Conditional discrimination vs. matching to sample: An expansion of the testing paradigm. Journal of the Experimental Analysis of Behavior. 37. 5-22. http://dx.doi.org/10.1901/jeab.1982.37-5

Sidman, M., Wynne, C. K., Maguire, R. W., \& Barnes, T. (1989). Functional classes and equivalence relations. Journal of the Experimental Analysis of Behavior. 52, 261-274. http://dx.doi.org/10.1901/jeab.1989.52-261

Skinner, B. F. (1974). About Behaviorism. London: Jonathon Cape.

Tajfel, H. (1974). Social identity and intergroup behavior. Social Science Information. 13,65-93. http://dx.doi.org/10.1177/053901847401300204

Tajfel, H. (Ed.). (1978). Differentiation between social groups: Studies in the social psychology of intergroup relations. European Monographs in Social Psychology. No. 14. London: Academic Press.

Trew, K. (1981). Intergroup relations and the development ofsocial identity in Northern Ireland. Paper presented at the sixth Biennial conference of the International Society for the Study of Behavioral Development. Ontario Institute for Studies in Education. Canada.

Trew, K. (1983). Group identification in a divided society. In 1. Harbison (Ed.), Children of the troubles: Children in Northern Ireland. Belfast: Stranmillis College, Learning Resources Unit.

Watt, A., Keenan, M., Barnes, D., \& Cairns, E. (1991). Social categorization and stimulus equivalence. The Psychological Record, 41, 33-50. 